\title{
An In Vivo Map of Bone Morphogenetic Protein 2 Post- transcriptional Repression in the Heart
}

\author{
Boudewijn P. T. Kruithof ${ }^{1}{ }^{,}$, Junwang $\mathrm{Xu}^{2,{ }^{*}}$, David T. Fritz ${ }^{2}$, Carolina S. Cabral ${ }^{1}$, Vinciane \\ Gaussin $^{1,{ }^{*}}$, and Melissa B. Rogers ${ }^{2,5}$ \\ ${ }^{1}$ Department of Cell Biology and Molecular Medicine, University of Medicine and Dentistry \\ (UMDNJ)-New Jersey Medical School (NJMS), Newark, NJ \\ ${ }^{2}$ Department of Biochemistry and Molecular Biology, UMDNJ-NJMS, Newark, NJ \\ ${ }^{3}$ Department of Cell and Developmental Biology, Vanderbilt University School of Medicine, \\ Nashville, TN \\ ${ }^{4}$ Department of Molecular Physiology and Biophysics, Center for Human Genetics Research, \\ Vanderbilt University School of Medicine, Nashville, TN
}

\begin{abstract}
The Bmp2 3'untranslated region (UTR) sequence bears a sequence conserved between mammals and fishes that can post-transcriptionally activate or repress protein synthesis. We developed a map of embryonic cells in the mouse where this potent $B m p 2$ regulatory sequence functions by using a lac Z reporter transgene with a 3'UTR bearing two lox $P$ sites flanking the ultra-conserved sequence. Cre-recombinase-mediated deletion of the ultra-conserved sequence caused strong ectopic expression in proepicardium, epicardium and epicardium-derived cells (EPDC) and in tissues with known epicardial contributions (coronary vessels and valves). Transient transfections of reporters in the epicardial/mesothelial cell (EMC) line confirmed this repression. Ectopic expression of the recombined transgene also occurred in the aorta, outlet septum, posterior cardiac plexus, cardiac and extra-cardiac nerves and neural ganglia. Bmp2 is dynamically regulated in the developing heart. 3'UTR-mediated mechanisms that restrain BMP2 synthesis may be relevant to congenital heart and vasculature malformations and to adult diseases involving aberrant BMP2 synthesis.
\end{abstract}

\section{Keywords}

mRNA; post-transcriptional; gene regulation; transgenic mice; aorta; coronary vasculature; epicardial cells; neural crest

\section{Introduction}

Bone morphogenetic protein (BMP)2 is an essential morphogen involved in numerous developmental and physiological processes (Chen et al., 2004; Hogan, 1996; Tsuji et al.,

\footnotetext{
${ }^{5}$ Address correspondence and requests for reprints to: Melissa B. Rogers, Biochemistry \& Molecular Biology (MSB E627), UMDNJ - New Jersey, Medical School, 185 South Orange Ave., P.O. Box 1709, Newark, NJ 07101-1709, Phone: (973) 972-2984, Fax: (973) 972-5594, rogersmb@umdnj.edu.

*Current addresses: B.P.T.K., Department of Medicine, Division of Cardiology, Weill Cornell Medical College, New York, NY; J.X., Department of Surgery, University of Mississippi Medical Center, Jackson, MS; V.G., Cardio3BioSciences, Mont-Saint-Guibert, Belgium

Author Disclosure Summary: B.P.T.K., D.T.F., J.X., C.S.C., V.G., and M.B.R. have nothing to disclose.
} 
2006; Zhang and Bradley, 1996). In particular, BMP2 signaling is required for essential aspects of heart development, including myocardial differentiation and survival, the development of the atrioventricular (AV) canal and outflow tract (OFT), valves, and the atrioventricular conduction (AVC) system ((Kirby, 2007) and refs. therein).

As expected for a morphogen, precise local regulation of BMP2 levels is crucial (Raftery and Sutherland, 2003; Zhang and Bradley, 1996). Different concentrations of active BMP2 or length of exposure regulate different cardiac genes to varying degrees (Alsan and Schultheiss, 2002; Schlange et al., 2000). A delicate balance between BMP2 signals and other signals such as FGF, control the behavior of proepicardial cells (Ishii et al., 2010; Kruithof et al., 2006; Schlueter et al., 2006; Torlopp et al., 2010; van Wijk et al., 2009). That appropriate levels of BMP2 are essential for normal development was shown by transgenic studies where BMP2 levels were experimentally elevated (Blessing et al., 1993) or reduced (Singh et al., 2008). As discussed below, post-transcriptional gene regulation mechanisms can control protein levels with precision during embryogenesis.

We have studied many aspects of Bmp2 gene regulation during the retinoic-acid (RA) induced differentiation of F9 embryonal carcinoma cells (Abrams et al., 2004; Fritz et al., 2006; Fritz et al., 2004; Heller et al., 1999; Hu et al., 2006; Rogers, 1996; Rogers et al., 1992). We have identified control regions that determine whether the Bmp2 gene is on or off (e.g., cell specific transcriptional enhancers) as well as elements that control the precise level of protein synthesis (e.g., translation efficiency and mRNA stability). An ultraconserved sequence (UCS) within the Bmp23'UTR is $73 \%$ identical over 265 nt. between mammals and fishes. Our bioinformatics comparisons to other highly conserved non-coding sequences established that this sequence ranks highly relative to other evolutionarily conserved sequences described to date (Abrams et al., 2004; Fritz et al., 2004). Our molecular analyses strongly suggests that this striking conservation reflects vital regulatory functions.

By analogy to numerous growth factors and cytokines (e.g., TNFa, interleukins) that are rapidly and dramatically regulated by 3'UTR elements, the 3'UTR is the logical location for mechanisms that regulate the BMP2 morphogen as precisely and dynamically as required in the heart. Our in vitro biochemistry and cell culture studies (Devaney et al., 2009; Fritz et al., 2006; Fritz et al., 2004; Jiang et al., 2010) demonstrated that the ultra-conserved sequence controls protein synthesis at the post-transcriptional level and acts as an autonomously acting repressor in normal lung and mesenchymal cells (Jiang et al., 2010; Kruithof et al., 2010a). We corroborated this model in neonatal and adult lung, aorta, and coronary vasculature by the in vivo deletion of the ultra-conserved sequence from a Bmp2driven lacZ transgene (Fritz et al., 2006; Jiang et al., 2010; Kruithof et al., 2010a).

Previous in vivo studies were guided by studies in cell types that exhibited ultra-conserved sequence-mediated repression in vitro. However, in the transgenic mouse, we observed many additional cell types where transgene expression was repressed by the ultra-conserved sequence. As in normal lung and mesenchymal cells, the Bmp2 gene may be transcribed, but BMP2 synthesis may be blocked at a post-transcriptional step. Because protein synthesis can be rapidly and precisely controlled by post-transcriptional means, such a mechanism would readily explain the dynamic patterns of $B m p 2$ expression observed in embryos. Identifying the cells poised to synthesize BMP2 in response to developmental signals is essential. We now provide a detailed map of the embryonic cells in which the ultra-conserved sequence represses gene expression. These include precursor cells of the coronary vasculature during development, including the proepicardium, and epicardium-derived cells and other specific cell types of cardiovascular relevance, including cells of the valves, outlet septum, posterior cardiac plexus, cardiac and extra-cardiac nerves. 


\section{Methods}

Animals

All animals were handled in accordance with the Guidelines for Care and Use of Experimental Animals and approved by the NJMS IACUC (protocols \#04086, \#00100). Procedures as described in (Kruithof et al., 2010a).

\section{Immunohistochemistry}

Whole-mount tissues stained for $\beta$ gal were embedded in paraffin and sectioned $(6 \mathrm{~mm})$. Sections were boiled for 20 minutes in $0.01 \mathrm{M}$ citrate buffer for antigen retrieval. For asmooth muscle actin (a-SMA) staining, sections were blocked with 5\% donkey serum in $0.1 \%$ Tween-20/PBS, incubated with primary antibodies against a-SMA (Dako North America, Inc., Carpinteria, CA), followed by Alexa-conjugated secondary antibody (Molecular Probes/Invitrogen, Carlsbad, CA) incubation to visualize the antibody binding. DAPI containing media (Vector) was used to visualize the nuclei. Because both DAPI and $\beta$ gal staining are blue, we used NIS-Elements Microscope Imaging Software (Nikon) to convert the DAPI to green for better contrast with $\beta$-gal.

For neurofilament 160 (NF160) staining, sections were treated with $3 \% \mathrm{H}_{2} \mathrm{O}_{2}$ to block endogenous peroxidase activity, blocked with 5\% horse serum, and incubated with NF160 antibody (Sigma). The Vectastain Elite ABC Kit and Novared Substrate kit (Vector) were used to visualize antibody binding.

\section{Tissue culture and transfections}

The rat epicardial/mesothelial cell (EMC) line (Eid et al., 1992) was grown in DMEM supplemented as described in (Wada et al., 2003). Cells were transfected using FuGene6 Transfection Reagent (Roche, Indianapolis, IN) following the manufacturer's protocol. 24 hrs after transfection, cells were lysed with 1X Passive Lysis Buffer (Promega, Madison, WI) and luciferase activities were measured using the Luciferase Assay System (Promega, Madison, WI) following the manufacturer's protocol. CMVLUCBmp (pCßSLucmHCNSPvAcGH) containing the mouse (9,574 nt to 9,938 nt) ultra-conserved sequences inserted downstream of luciferase in CMVLUC (pC $\beta S L u c$ ) was described in (Devaney et al., 2009).

\section{Results}

\section{Transgenic reporter genes mimic endogenous Bmp2 expression patterns}

To map where the ultra-conserved sequence functions in vivo, we used a transgenic mouse strain bearing a lac $Z$ transgene driven by the mouse $B m p 2$ promoter region, the entire $B m p 2$ 3'UTR and 934 nt of downstream sequence (Fritz et al., 2006). Two loxP sites flanking the ultra-conserved sequence in the reporter gene (Figure (Fig.) 1A) permitted its in vivo excision by Cre-recombinase (Jiang et al., 2010; Kruithof et al., 2010a). Supplemental Fig. 1 shows that the expression of the intact $B m p 2$ reporter gene in several structures closely resembles published patterns of $B m p 2$ expression at these stages. These representative images (Supplemental Fig. 1, $\mathrm{n}=10-20$ embryos) show expected embryonic patterns in pericardial mesoderm (Zhang and Bradley, 1996), interdigital cells of the developing paw (Laufer et al., 1997; Salas-Vidal et al., 2001), eye (Belecky-Adams and Adler, 2001; Dudley and Robertson, 1997; Furuta et al., 1997), cartilage primordium (Lyons et al., 1989), and trigeminal nerves (Jin et al., 2001). Similar expression patterns also were observed in congenic mice backcrossed into the C57B1/6 strain for 10 generations (not shown). The reporter gene was not expressed in some embryonic tissues that do express $B m p 2$ such as the atrioventricular canal (AVC) (Abdelwahid et al., 2001) and the condensing mesenchyme 
and hypertrophic cartilage of the long bones (Lyons et al., 1989). This was expected for this transgene, because other studies have identified extremely distant Bmp2 regulatory regions (Chandler et al., 2007). Thus several, although not all, BMP2-expressing tissues also express this reporter gene.

\section{Deletion of the ultra-conserved region induces reporter gene expression in vivo}

We queried the embryonic regions where the ultra-conserved region represses gene expression by deleting the ultra-conserved region in the Bmp2 reporter gene using a ubiquitously expressed Cre-recombinase (Schwenk et al., 1995). Deletion caused the $\beta$ gal pattern to expand beyond the regions where the intact reporter gene was expressed (Fig. 1). For example, in the trigeminal nerves, $\beta$ gal staining outlines the termini of the nerve network in mice with the intact transgene (no Cre, Fig. 1C). In the Cre-expressing mice, terminal expression appears intensified and the field of expression clearly extends back into the nerve cell bodies. $\beta$ gal staining also occurred in the dorsal root ganglia of Cre-expressing mice (Fig. 1). Because BMP2 is an essential signal during the development of the heart and cardiovasculature, we carried out a detailed analysis of reporter gene expression in these tissues.

\section{Ultra-conserved sequence-mediated repression in proepicardial, epicardial and coronary vascular cells in vivo and recapitulation of ultra-conserved sequence-mediated inhibition in cultured epicardial cells}

Proepicardial cells have been extensively shown to differentiate into coronary endothelial, smooth muscle and fibroblastic cells both in vivo and in vitro (Dettman et al., 1998; Grieskamp et al., 2011; Olivey et al., 2004; Reese et al., 2002; Wessels and Perez-Pomares, 2004; Winter and Gittenberger-de Groot, 2007). A recent report suggests that coronary endothelium also forms from the outgrowth of the sinus venosus endothelium (Red-Horse et al., 2010). Fig. 2 demonstrates that proepicardial (embryonic day E10.0; Fig. 2A), epicardial (Fig. 2B) and subepicardial cells (E11.5, E12.5; Fig. 2B, D) express the transgene specifically in Cre-expressing mice. In contrast, the epicardium of no Cre embryos showed little, if any, expression of the intact transgene, although the intact transgene was expressed in the pericardium (Fig. 2C). Expression in the epicardium appeared to decrease after birth (Fig. 2H). Immunohistochemical analyses using a-smooth muscle actin (SMA) and cell morphologies established that the ultra-conserved sequence repressed $\beta$ gal synthesis in vascular epicardium-derived cells: a subset of coronary endothelial cells (EC), smooth muscle cells (SMC) and perivascular fibroblasts (PF) (Fig. 2F-G).

Previously, we first established that the ultra-conserved sequence repressed protein synthesis in specific cell types in vitro and then subsequently verified the phenomenon in vivo (Jiang et al., 2010; Kruithof et al., 2010a). Now, guided by the in vivo results, we describe a new in vitro model of Bmp2 gene repression. The rat epicardial/mesothelial cell (EMC) line (Eid et al., 1992; Wada et al., 2003) has been used to map the epicardial control region derived from the chick GATA-5 gene (Burch, 2005; MacNeill et al., 2000). Fig. 2E demonstrates that the ultra-conserved sequence significantly repressed reporter genes driven by a heterologous cytomegalovirus (CMV) promoter (compare CMVLuc to CMVLUCBmp) in the EMC line, thus corroborating the in vivo transgene repression in embryonic epicardial cells. In summary, we have demonstrated that the ultra-conserved sequence inhibits gene expression in cells of known epicardial origin. Furthermore, we have identified a new cell culture model of this repression. 


\section{Ultra-conserved sequence-mediated repression in cardiac cushions, valves, aorta, and pulmonary trunk}

In the outflow tract (OFT), cushions are formed that will give rise to the outlet septum and the semilunar (aortic and pulmonary) valves (Kirby, 2007). The recombined Bmp2 reporter transgene was expressed in the distal cushions (Fig. 3A; Supp. Fig. 2A) and outlet septum (Fig. 3B; Supp. Fig. 2B, C) of the OFT in +Cre embryos, whereas expression was absent in these tissues in no Cre embryos (Fig. 3C). In E18.5 +Cre embryos, transgene expression was observed in the developing aortic, but not the pulmonary, valve near the attachment to the vessel wall (Fig. 3G). After birth, both valves had blue cells near the attachment (N0.5 and N4.5, not shown). Subsequently in the adult, the number of blue cells in the valves was increased and they were located nearer the distal side of the leaflets (Fig. 3H).

The recombined $B m p 2$ reporter gene was robustly expressed in all smooth muscle cells of both the ascending and descending aorta of + Cre mice in adult mice (Kruithof et al., 2010a). Here we show that transgene expression in + Cre embryos was detectable in the aorta at E13.5 (Fig. 3D). In contrast, expression of the recombined Bmp2 reporter gene was delayed in the pulmonary trunk until E15.5 (Fig. 3F).

In the region of the inflow tract (IFT), we observed expression of the recombined transgene in the dorsal mesenchymal protrusion (DMP) and the inferior atrioventricular (AV) cushions (Fig. 3I), which will contribute to the AV septum and septal leaflets of the AV valves (mitral and tricuspid valves). Expression also occurred in the dorsal mesocardium (DM; Figs. 2D, 3I), which connects the DMP to the dorsal body wall. Transgene expression was observed in the septal leaflets of the AV valves from E15.5 (Fig. 3J; Supp. Fig. 2D) and in the mural leaflets of the AV valves from E18.5 in +Cre embryos. This was predominantly in the proximal leaflet portion adjacent to the annulus fibrosus and at the attachment to the papillary muscle (Fig. 3K). At N13.5, expression of the recombined Bmp2 transgene had expanded and was located mainly at the ventricular side of the AV valves (Fig. 3M). In all locations, expression was undetectable in littermates without the Cre gene (not shown).

The AV valves contain pigmented melanocytes from about E17.5 (Mjaatvedt et al., 2005). Pigmented melanocytes developed in our mice, because the CMV-Cre parent was strain C57Bl/6. At E18.5, a subset of the $\beta$ gal-positive cells in the septal leaflets of the AV valves also was pigmented (Fig. 3L). Together, these observations reveal spatial and temporal differences in the acquisition of the repression mechanism mediated by the Bmp2 ultraconserved sequence.

\section{Ultra-conserved sequence-mediated repression in other cardiac and extra-cardiac tissues}

From E15.5 onwards, $\beta$ gal expression resulting from the recombined transgene was observed in the ventricular myocardium close to the apex of the heart, exclusively in Crepositive mice. This expression remained after birth (Fig. 4A). Expanded expression of the recombined transgene lacking the ultra-conserved sequence was previously noted in the trigeminal nerves and dorsal root ganglia (Fig. 1). Staining for neurofilament 160 also colocalized with $\beta$ gal in Cre-expressing embryos in neurons inside and outside the developing heart. These included the dorsal root ganglia (E11.5, Fig. 1C, D; 4B), vagal nerve (Fig. 4C), cardiac plexus (Fig. 4F), and nerves surrounding the venous pole and on the atrial wall (Fig. 4E, F). Neural expression was absent in littermates without the Cre gene (Fig. 4D and not shown). 


\section{Discussion}

\section{Gene proximal elements functioning in a subset of Bmp2-expressing tissues}

The intact reporter bearing $3.9 \mathrm{~kb}$ of $B m p 2$ non-coding sequence was expressed in several tissues that synthesize BMP2 (pericardial mesoderm, interdigital cells, eye, cartilage primordium, and trigeminal nerves (Belecky-Adams and Adler, 2001; Dudley and Robertson, 1997; Furuta et al., 1997; Jin et al., 2001; Laufer et al., 1997; Lyons et al., 1989; Salas-Vidal et al., 2001; Zhang and Bradley, 1996). Thus elements that drive expression in these tissues map to the distal promoter region or within $2.2 \mathrm{~kb}$ of the stop codon. Extremely distant Bmp2 regulatory regions explain incomplete recapitulation of the endogenous BMP2 pattern (Chandler et al., 2007).

\section{Two general repression patterns}

In some embryonic regions, deletion of the UCS caused expansion of $\beta$ gal into cells adjacent to regions that expressed the intact transgene. The trigeminal nerves illustrate this pattern (Fig. 1). In other cells, expression of the intact transgene was not detectable, but the recombined transgene was strongly expressed. Using biochemically tractable systems, we and others proved that the UCS functions post-transcriptionally in diverse cell types (Devaney et al., 2009; Fritz et al., 2006; Fritz et al., 2004; Fukui et al., 2006; Jiang et al., 2010; Kruithof et al., 2010b). The ectopic expression caused by removing the UCS revealed cells that can synthesize BMP2 quickly in response to local developmental stimuli, as typifies many potent cytokines and growth factors.

\section{Potential lineage-specific activation of regulatory elements}

After deletion of the UCS, Bmp2 transgene expression was observed in proepicardium, epicardium, subepicardium, coronary endothelial cells, smooth muscle cells, and perivascular fibroblasts suggesting that epicardial lineage specific elements reside in the 3.1 $\mathrm{kb}$ of Bmp2 DNA remaining in the recombined transgene. Prior to our study, only one other regulatory region that could activate transgene expression in epicardial cells in vivo and in the rat epicardial/mesothelial cell (EMC) line had been delineated; chick GATA-5 (MacNeill et al., 2000). Elucidating gene regulatory processes in these essential cells requires characterizing these epicardial-specific control modules.

Both cardiac and extra-cardiac structures with known neural crest cell contributions (OFT cushions, outlet septum, mesenchymal inflow structures, AV valves, posterior cardiac plexus, cardiac and extra-cardiac nerves) expressed the recombined Bmp2 transgene (Figs. 3, 4; (Brito and Kos, 2008; Hildreth et al., 2008; Jiang et al., 2000; Nakamura et al., 2006). The versatile cranial neural crest cells provide both instructive signals and structural components to the heart, vasculature, and associated nerves. These cells may rapidly release BMP2 in response to local stimuli.

\section{UCS-mediated repression varies in time and space}

Although the recombined transgene was widely expressed, the expression was dynamic. Whereas virtually all +Cre epicardial cells were positive at E11.5, only a subset of the epicardium-derived cells were positive later. Such changeable expression is consistent with cells encountering different environments and suggests that local signals modulate the balance of positive and negative gene regulatory factors in these cells. For example, widespread expression of the recombined transgene in large coronary vessels and along the ventricular side of the mitral and tricuspid leaflets suggests that a hemodynamic component may activate the transgene (Kruithof et al., 2007). Non-uniform labeling in all endothelial cells also may reflect multiple origins (Cai et al., 2008; Red-Horse et al., 2010; Zhou et al., 2008). 


\section{Potential regulators}

We have identified three cultured cell types that retain the unique and unexpected aspect of Bmp2 repression observed in vivo. The UCS represses gene expression in mouse epicardial cells in vivo and in the rat epicardial/mesothelial cell (EMC) model of these cells (Fig. 2, (Eid et al., 1992; Wada et al., 2003)); in mesenchymal cells of the mouse aorta and coronary vasculature in vivo and in C3H10T1/2 mesenchymal cells (Fig. 3, (Devaney et al., 2009; Kruithof et al., 2010a)); and in mouse lung in vivo and in BEAS-2B immortalized bronchial epithelial cells (Jiang et al., 2010). With these three tissue culture models of the repressive function seen in three in vivo tissues, we can identify the biochemical mechanisms that mediate repression.

Potential regulatory molecules include proteins; e.g., HuR and nucleolin (Devaney et al., 2009; Fritz et al., 2006) and microRNAs (Jing et al., 2005; Wu et al., 2006; Zhao and Srivastava, 2007). Hybridization to conserved anti-sense miRNAs would explain some of the extraordinary sequence identity between vertebrate Bmp23'UTRs. Furthermore, Cremediated deletion of the UCS from the recombined $B m p 2$ reporter gene would render the reporter mRNAs immune to microRNA-mediated repression. Over 40 microRNAs have been computationally predicted to interact with the Bmp23'UTR, a majority within the UCS (http://www.targetscan.org and http://pictar.bio.nyu.edu). Tests of microRNA function including mutations of putative binding sites are currently in progress. Understanding the molecules that sustain or release this braking mechanism is directly relevant to the etiology of congenital malformations of the heart and vasculature and to adult diseases involving abnormal BMP2 production.

\section{Supplementary Material}

Refer to Web version on PubMed Central for supplementary material.

\section{Acknowledgments}

We thank Dr. David Bader, Vanderbilt University for the rat epicardial/mesothelial (EMC) line.

Grant Sponsors: This work was supported in part by the Molecular Resource Facility at the UMDNJ - NJ Medical School (M.B.R.), the Foundation of UMDNJ (M.B.R.), the National Institute of Health (R01HD31117 to M.B.R., R21HL084278 to V.G..), the American Heart Association (00655881T to M.B.R., 555840T to V.G., and 0625861T to B.P.T.K.), and the March of Dimes Birth Defects Foundation (1-FY06-375 to V.G.).

\section{References}

Abdelwahid E, Rice D, Pelliniemi LJ, Jokinen E. Overlapping and differential localization of Bmp-2, Bmp-4, Msx-2 and apoptosis in the endocardial cushion and adjacent tissues of the developing mouse heart. Cell Tissue Res. 2001; 305:67-78. [PubMed: 11512673]

Abrams KL, Xu J, Nativelle-Serpentini C, Dabirshahsahebi S, Rogers MB. An evolutionary and molecular analysis of Bmp2 expression. J Biol Chem. 2004; 279:15916-15928. [PubMed: 14757762]

Alsan BH, Schultheiss TM. Regulation of avian cardiogenesis by Fgf8 signaling. Development. 2002; 129:1935-1943. [PubMed: 11934859]

Belecky-Adams T, Adler R. Developmental expression patterns of bone morphogenetic proteins, receptors, and binding proteins in the chick retina. J Comp Neurol. 2001; 430:562-572. [PubMed: 11169487]

Blessing M, Nanney LB, King LE, Jones CM, Hogan BL. Transgenic mice as a model to study the role of TGF-beta-related molecules in hair follicles. Genes Dev. 1993; 7:204-215. [PubMed: 8436293]

Brito FC, Kos L. Timeline and distribution of melanocyte precursors in the mouse heart. Pigment Cell Melanoma Res. 2008; 21:464-470. [PubMed: 18444965] 
Burch JB. Regulation of GATA gene expression during vertebrate development. Semin Cell Dev Biol. 2005; 16:71-81. [PubMed: 15659342]

Chandler RL, Chandler KJ, McFarland KA, Mortlock DP. Bmp2 transcription in osteoblast progenitors is regulated by a distant 3 ' enhancer located 156.3 kilobases from the promoter. Mol Cell Biol. 2007; 27:2934-2951. [PubMed: 17283059]

Chen D, Zhao M, Mundy GR. Bone morphogenetic proteins. Growth Factors. 2004; 22:233-241. [PubMed: 15621726]

Dettman RW, Denetclaw W Jr, Ordahl CP, Bristow J. Common epicardial origin of coronary vascular smooth muscle, perivascular fibroblasts, and intermyocardial fibroblasts in the avian heart. Dev Biol. 1998; 193:169-181. [PubMed: 9473322]

Devaney JM, Tosi LL, Fritz DT, Gordish-Dressman HA, Jiang S, Orkunoglu-Suer FE, Gordon AH, Harmon BT, Thompson PD, Clarkson PM, Angelopoulos TJ, Gordon PM, Moyna NM, Pescatello LS, Visich PS, Zoeller RF, Brandoli C, Hoffman EP, Rogers MB. Differences in fat and muscle mass associated with a functional human polymorphism in a post-transcriptional BMP2 gene regulatory element. J Cell Biochem. 2009; 107:1073-1082. [PubMed: 19492344]

Dudley AT, Robertson EJ. Overlapping expression domains of bone morphogenetic protein family members potentially account for limited tissue defects in BMP7 deficient embryos. Dev Dyn. 1997; 208:349-362. [PubMed: 9056639]

Eid H, Larson DM, Springhorn JP, Attawia MA, Nayak RC, Smith TW, Kelly RA. Role of epicardial mesothelial cells in the modification of phenotype and function of adult rat ventricular myocytes in primary coculture. Circ Res. 1992; 71:40-50. [PubMed: 1606667]

Fritz DT, Jiang S, Xu J, Rogers MB. A polymorphism in a conserved posttranscriptional regulatory motif alters bone morphogenetic protein 2 (BMP2) RNA:protein interactions. Mol Endocrinol. 2006; 20:1574-1586. [PubMed: 16497730]

Fritz DT, Liu D, Xu J, Jiang S, Rogers MB. Conservation of Bmp2 post-transcriptional regulatory mechanisms. J Biol Chem. 2004; 279:48950-48958. [PubMed: 15358784]

Fukui N, Ikeda Y, Ohnuki T, Hikita A, Tanaka S, Yamane S, Suzuki R, Sandell LJ, Ochi T. Proinflammatory cytokine tumor necrosis factor-alpha induces bone morphogenetic protein-2 in chondrocytes via mRNA stabilization and transcriptional up-regulation. J Biol Chem. 2006; 281:27229-27241. [PubMed: 16835229]

Furuta Y, Piston DW, Hogan BL. Bone morphogenetic proteins (BMPs) as regulators of dorsal forebrain development. Development. 1997; 124:2203-2212. [PubMed: 9187146]

Grieskamp T, Rudat C, Ludtke TH, Norden J, Kispert A. Notch Signaling Regulates Smooth Muscle Differentiation of Epicardium-Derived Cells. Circ Res. 2011

Heller LC, Li Y, Abrams KA, Rogers MB. Transcriptional Regulation of the Bmp2 Gene: Retinoic Acid Induction in F9 Embryonal Carcinoma Cells and Saccharomyces cerevisiae. J Biol Chem. 1999; 274:1394-1400. [PubMed: 9880512]

Hildreth V, Webb S, Bradshaw L, Brown NA, Anderson RH, Henderson DJ. Cells migrating from the neural crest contribute to the innervation of the venous pole of the heart. J Anat. 2008; 212:1-11. [PubMed: 18031480]

Hogan B. Bone morphogenetic proteins: multifunctional regulators of vertebrate development. Genes Dev. 1996; 10:1580-1594. [PubMed: 8682290]

Hu, J.; Fritz, DT.; Tian, B.; Rogers, MB. ACM First International Workshop on Text Mining in Bioinformatics (TMBIO2006) Proceedings. Arlington, VA, USA. New York, NY: ACM Press; 2006. Using Emerging Genome Data to Identify Conserved Bone Morphogenetic Protein (Bmp)2 Gene Expression Mechanisms.

Ishii Y, Garriock RJ, Navetta AM, Coughlin LE, Mikawa T. BMP signals promote proepicardial protrusion necessary for recruitment of coronary vessel and epicardial progenitors to the heart. Dev Cell. 2010; 19:307-316. [PubMed: 20708592]

Jiang S, Fritz DT, Rogers MB. A conserved post-transcriptional BMP2 switch in lung cells. J Cell Biochem. 2010; 110:509-521. [PubMed: 20432245]

Jiang X, Rowitch DH, Soriano P, McMahon AP, Sucov HM. Fate of the mammalian cardiac neural crest. Development. 2000; 127:1607-1616. [PubMed: 10725237] 
Jin Y, Lu HB, Liong E, Lau TY, Tipoe GL. Transcriptional mRNA of BMP-2-3-4 and 5 in trigeminal nerve, benign and malignant peripheral nerve sheath tumors. Histol Histopathol. 2001; 16:10131019. [PubMed: 11642720]

Jing Q, Huang S, Guth S, Zarubin T, Motoyama A, Chen J, Di Padova F, Lin SC, Gram H, Han J. Involvement of microRNA in AU-rich element-mediated mRNA instability. Cell. 2005; 120:623634. [PubMed: 15766526]

Kirby, ML. Cardiac development. Oxford ; New York: Oxford University Press; 2007. p. 273

Kruithof B, Fritz D, Liu Y, Garsetti D, Frank D, Pregizer S, Gaussin V, Mortlock D, Rogers M. An Autonomous BMP2 Regulatory Element in Mesenchymal Cells. J Cell Biochem. 2010a in press.

Kruithof BP, Fritz DT, Liu Y, Garsetti DE, Frank DB, Pregizer SK, Gaussin V, Mortlock DP, Rogers MB. An autonomous BMP2 regulatory element in mesenchymal cells. J Cell Biochem. 2010b; 112:666-674. [PubMed: 21268088]

Kruithof BP, Krawitz SA, Gaussin V. Atrioventricular valve development during late embryonic and postnatal stages involves condensation and extracellular matrix remodeling. Dev Biol. 2007; 302:208-217. [PubMed: 17054936]

Kruithof BP, van Wijk B, Somi S, Kruithof-de Julio M, Perez Pomares JM, Weesie F, Wessels A, Moorman AF, van den Hoff MJ. BMP and FGF regulate the differentiation of multipotential pericardial mesoderm into the myocardial or epicardial lineage. Dev Biol. 2006; 295:507-522. [PubMed: 16753139]

Laufer E, Pizette S, Zou H, Orozco OE, Niswander L. BMP expression in duck interdigital webbing: a reanalysis. Science. 1997; 278:305. [PubMed: 9340773]

Lyons K, Pelton R, Hogan B. Patterns of expression of murine Vgr-1 and BMP-2a RNA suggest that transforming growth factor-b-like genes coordinately regulate aspects of embryonic development. Genes \& Devl. 1989; 3:1657-1668.

MacNeill C, French R, Evans T, Wessels A, Burch JB. Modular regulation of cGATA-5 gene expression in the developing heart and gut. Dev Biol. 2000; 217:62-76. [PubMed: 10625536]

Mjaatvedt CH, Kern CB, Norris RA, Fairey S, Cave CL. Normal distribution of melanocytes in the mouse heart. Anat Rec A Discov Mol Cell Evol Biol. 2005; 285:748-757. [PubMed: 15977222]

Nakamura T, Colbert MC, Robbins J. Neural crest cells retain multipotential characteristics in the developing valves and label the cardiac conduction system. Circ Res. 2006; 98:1547-1554. [PubMed: 16709902]

Olivey HE, Compton LA, Barnett JV. Coronary vessel development: the epicardium delivers. Trends Cardiovasc Med. 2004; 14:247-251. [PubMed: 15451517]

Raftery LA, Sutherland DJ. Gradients and thresholds: BMP response gradients unveiled in Drosophila embryos. Trends Genet. 2003; 19:701-708. [PubMed: 14642751]

Red-Horse K, Ueno H, Weissman IL, Krasnow MA. Coronary arteries form by developmental reprogramming of venous cells. Nature. 2010; 464:549-553. [PubMed: 20336138]

Reese DE, Mikawa T, Bader DM. Development of the coronary vessel system. Circ Res. 2002; 91:761-768. [PubMed: 12411389]

Rogers M. Receptor-selective retinoids implicate RAR alpha and gamma in the regulation of bmp-2 and bmp-4 in F9 embryonal carcinoma cells. Cell Growth Differ. 1996; 7:115-122. [PubMed: 8788040]

Rogers MB, Rosen V, Wozney JM, Gudas LJ. Bone Morphogenetic Proteins-2 and 4 are Involved in the Retinoic Acid-induced Differentiation of Embryonal Carcinoma Cells. Molec Biol Cell. 1992; 3:189-196. [PubMed: 1550961]

Salas-Vidal E, Valencia C, Covarrubias L. Differential tissue growth and patterns of cell death in mouse limb autopod morphogenesis. Dev Dyn. 2001; 220:295-306. [PubMed: 11307164]

Schlange T, Andree B, Arnold HH, Brand T. BMP2 is required for early heart development during a distinct time period. Mech Dev. 2000; 91:259-270. [PubMed: 10704850]

Schlueter J, Manner J, Brand T. BMP is an important regulator of proepicardial identity in the chick embryo. Dev Biol. 2006; 295:546-558. [PubMed: 16677627]

Schwenk F, Baron U, Rajewsky K. A cre-transgenic mouse strain for the ubiquitous deletion of loxPflanked gene segments including deletion in germ cells. Nucleic Acids Res. 1995; 23:5080-5081. [PubMed: 8559668] 
Singh AP, Castranio T, Scott G, Guo D, Harris MA, Ray M, Harris SE, Mishina Y. Influences of reduced expression of maternal bone morphogenetic protein 2 on mouse embryonic development. Sex Dev. 2008; 2:134-141. [PubMed: 18769073]

Torlopp A, Schlueter J, Brand T. Role of fibroblast growth factor signaling during proepicardium formation in the chick embryo. Dev Dyn. 2010; 239:2393-2403. [PubMed: 20683934]

Tsuji K, Bandyopadhyay A, Harfe BD, Cox K, Kakar S, Gerstenfeld L, Einhorn T, Tabin CJ, Rosen V. BMP2 activity, although dispensable for bone formation, is required for the initiation of fracture healing. Nat Genet. 2006; 38:1424-1429. [PubMed: 17099713]

van Wijk B, van den Berg G, Abu-Issa R, Barnett P, van der Velden S, Schmidt M, Ruijter JM, Kirby ML, Moorman AF, van den Hoff MJ. Epicardium and myocardium separate from a common precursor pool by crosstalk between bone morphogenetic protein- and fibroblast growth factorsignaling pathways. Circ Res. 2009; 105:431-441. [PubMed: 19628790]

Wada AM, Smith TK, Osler ME, Reese DE, Bader DM. Epicardial/Mesothelial cell line retains vasculogenic potential of embryonic epicardium. Circ Res. 2003; 92:525-531. [PubMed: 12600887]

Wessels A, Perez-Pomares JM. The epicardium and epicardially derived cells (EPDCs) as cardiac stem cells. Anat Rec A Discov Mol Cell Evol Biol. 2004; 276:43-57. [PubMed: 14699633]

Winter EM, Gittenberger-de Groot AC. Epicardium-derived cells in cardiogenesis and cardiac regeneration. Cell Mol Life Sci. 2007; 64:692-703. [PubMed: 17380310]

Wu L, Fan J, Belasco JG. MicroRNAs direct rapid deadenylation of mRNA. Proc Natl Acad Sci U S A. 2006; 103:4034-4039. [PubMed: 16495412]

Zhang H, Bradley A. Mice deficient for BMP2 are nonviable and have defects in amnion/chorion and cardiac development. Devl. 1996; 122:2977-2986.

Zhao Y, Srivastava D. A developmental view of microRNA function. Trends Biochem Sci. 2007; 32:189-197. [PubMed: 17350266] 


\section{A. Intact transgene (no Cre)}

\section{B. E10.5}

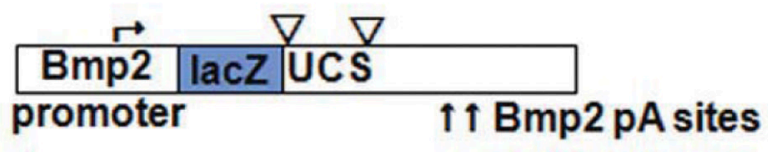

Recombined transgene with deletion (+ Cre)

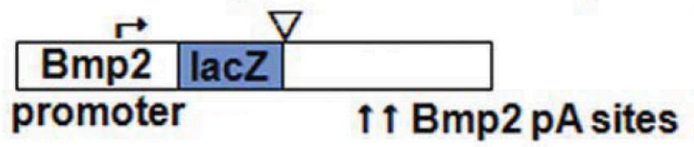

\section{C.E12.5}
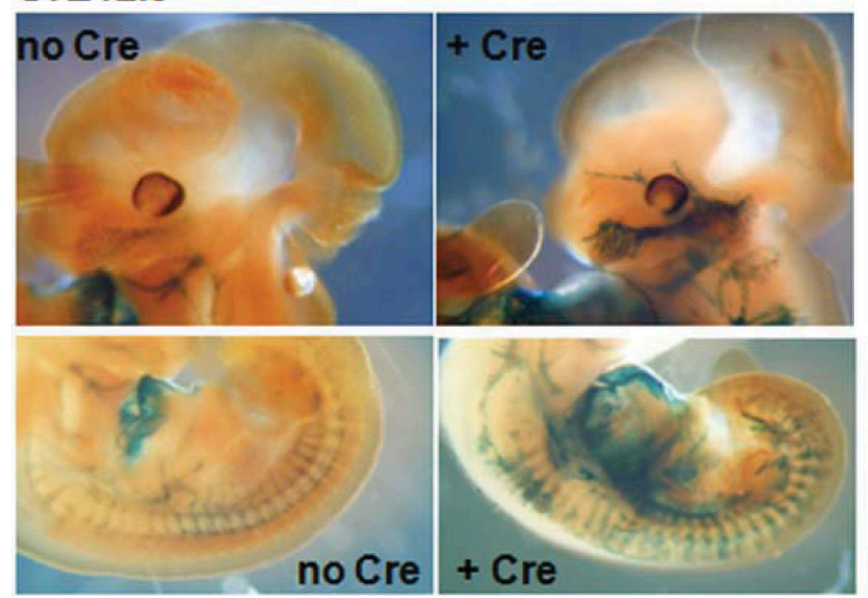

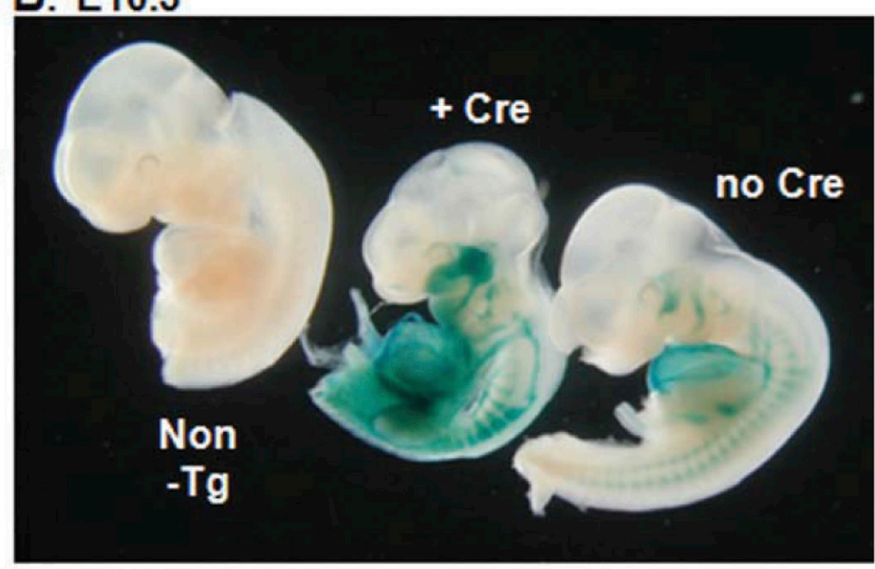

D. E13.5
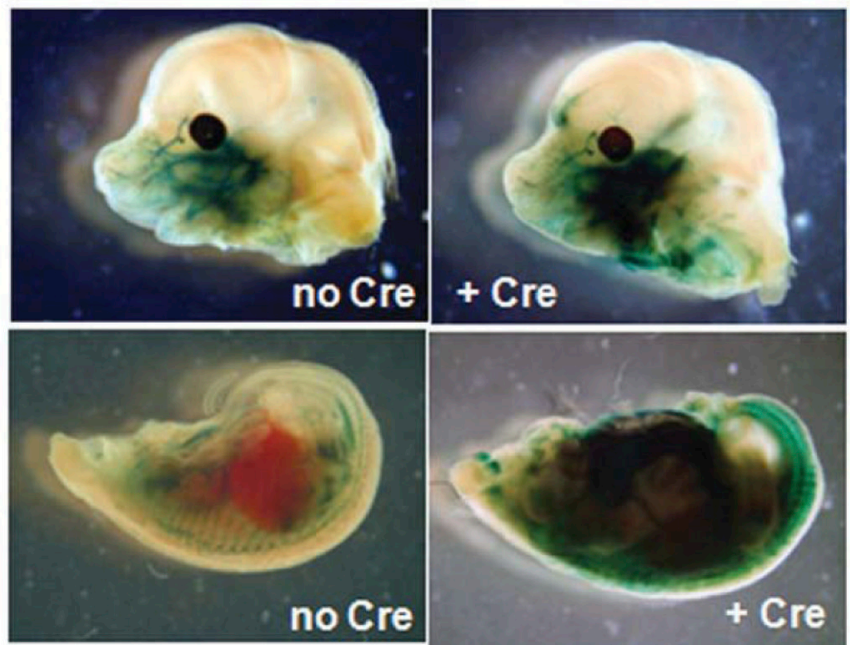

Fig. 1. Cre-mediated deletion of the ultra-conserved region activates reporter gene expression in embryos

A. Diagrams of a reporter transgene with the murine $B m p 2$ promoter $(\Gamma, \mathrm{nt}-1237$ to 471$)$ and 3'UTR regions (nt 9392 to 11604) flanking the lac $Z$ gene. $\nabla$ marks the lox $P$ sites flanking the ultra-conserved sequence (UCS, nt 9392 to 10200). The approximate locations of the 2 natural Bmp2 poly(A) signals at 10,332 and 10,619 (Fritz et al., 2004) relative to the promoter (yielding 3'UTRs of $\sim 870$ and $1175 \mathrm{nt}$, respectively) are indicated by arrows ( $\uparrow$ ). B - D. Mice carrying the Bmp2 transgene were mated with mice hemizygous for a Crerecombinase gene driven by the ubiquitously expressed CMV promoter. Embryo littermates (ages indicated in panels) were whole mount stained for $\beta$ gal (blue staining). The domains of $\beta$ gal activity intensified and expanded in + Cre animals. 
A. $\mathrm{E} 10.0+\mathrm{Cre}$

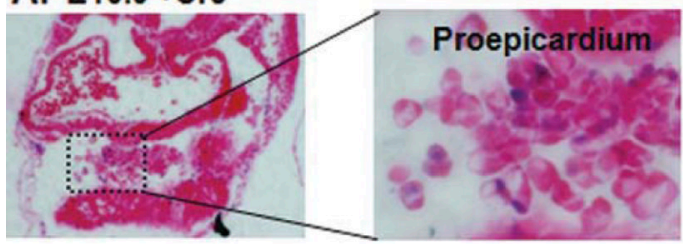

B. E11.5 +Cre

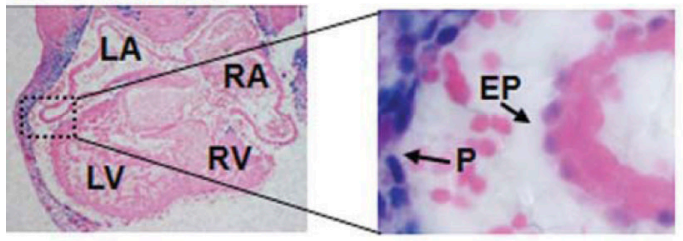

C. E11.5 No Cre

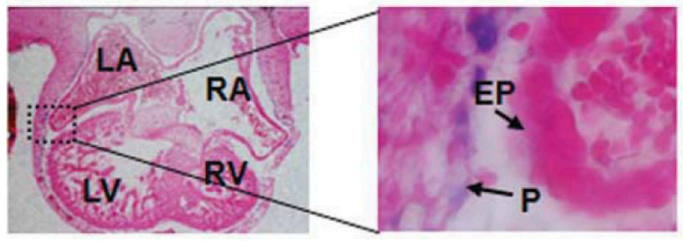

F.E18.5 embryo +Cre
D. $\mathrm{E} 12.5+\mathrm{Cre}$

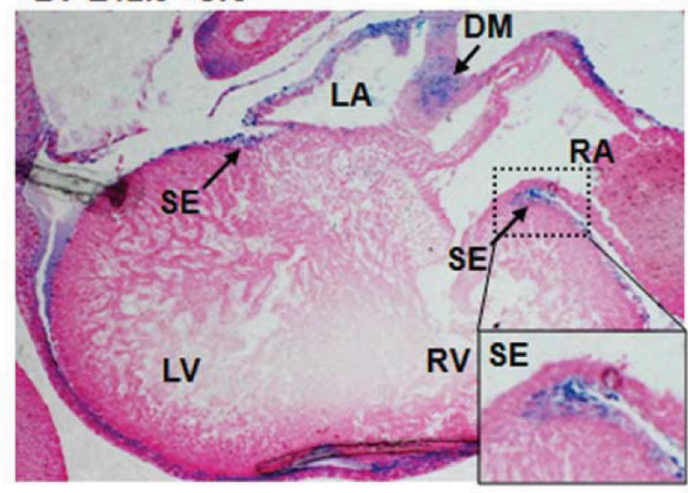

E. rat epicardial/mesothelial (EMC) cells

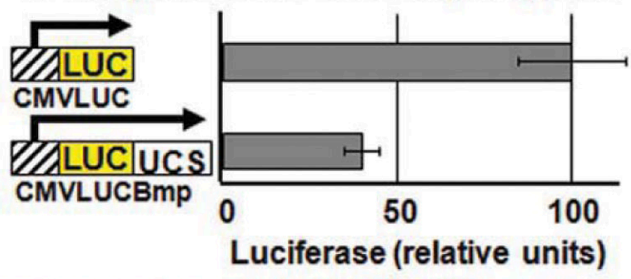

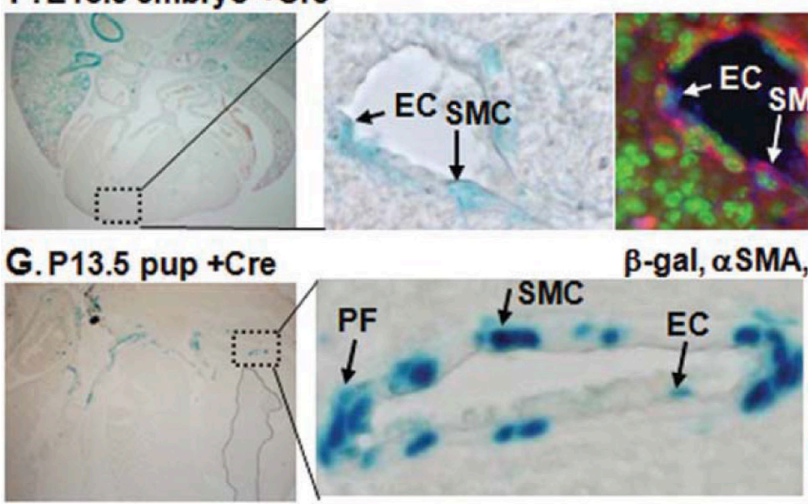

G.P13.5 pup + Cre

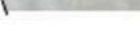

\section{H. P13.5 pup +Cre, veins}

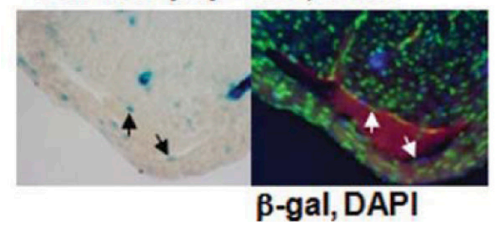

Fig. 2. Proepicardium and epicardium express the recombined reporter transgene in + Cre mice Sections of whole-mount $\beta$ gal-stained (blue) Cre-expressing embryos. A. E10.0 embryos $(+\mathrm{Cre})$ express the transgene in proepicardium. B, C. E11.5 embryos with both the recombined ( $+\mathrm{Cre}$ ) and the intact (no Cre) transgenes contain $\beta$ gal-positive cells in the pericardial mesoderm. Only + Cre embryos also express the transgene in the epicardium (EP). D. In E12.5 embryos (+Cre), transgene expression is also observed in subepicardial (SE) cells and dorsal mesocardium (DM; also see Fig. 3). Left atrium (LA), right atrium (RA), left ventricle (LV), right ventricle (RV), dorsal mesocardium (DM). E. Luciferase activity generated in rat epicardial/mesothelial cells (EMC) after transfection with reporter 
genes driven by the constitutive cytomegalovirus (CMV) promoter with (CMVLUCBmp) or without (CMVLUC) the mouse ultra-conserved sequence (UCS, nt 9574-10204 relative to the mouse distal promoter) inserted downstream of LUC. Relative reporter activity is shown \pm SEM, $n=8$. F-H. Sections were immuno-histochemically stained with an antibody against a smooth muscle actin (a-SMA, red). Some sections were counterstained with DAPI (green) to mark nuclei. The merged images illustrate colocalization of $\beta$ gal activity with endothelial cells (EC) and a-SMA positive smooth muscle cells (SMC) and perivascular fibroblasts $(\mathbf{P F})$. F and $\mathbf{G}$ show coronary arteries at E18.5 and P13.5, respectively. $\mathbf{H}$ shows a section of a coronary vein with $\beta$ gal-positive endothelial cells at P13.5. 


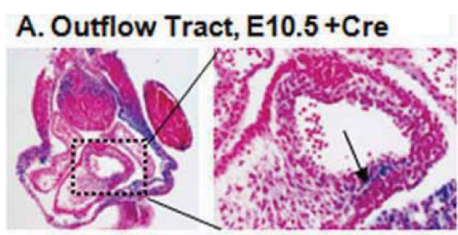

D. E13.5 +cre

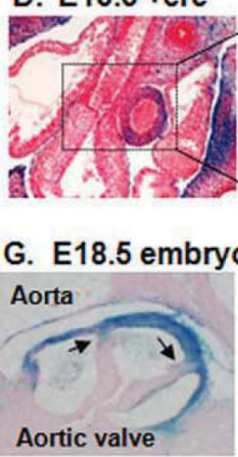

Pulmonary valve

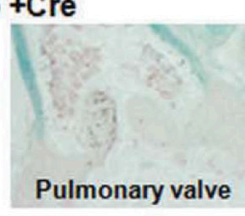

B. Outflow Septum, E13.5 +Cre

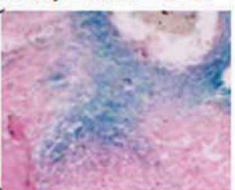

C. Outflow Septum, E13.5 no Cre

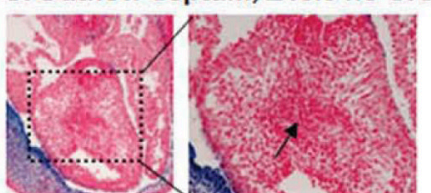

E. 13.5 no Cre

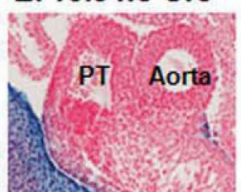

\section{F. E15.5 +cre}
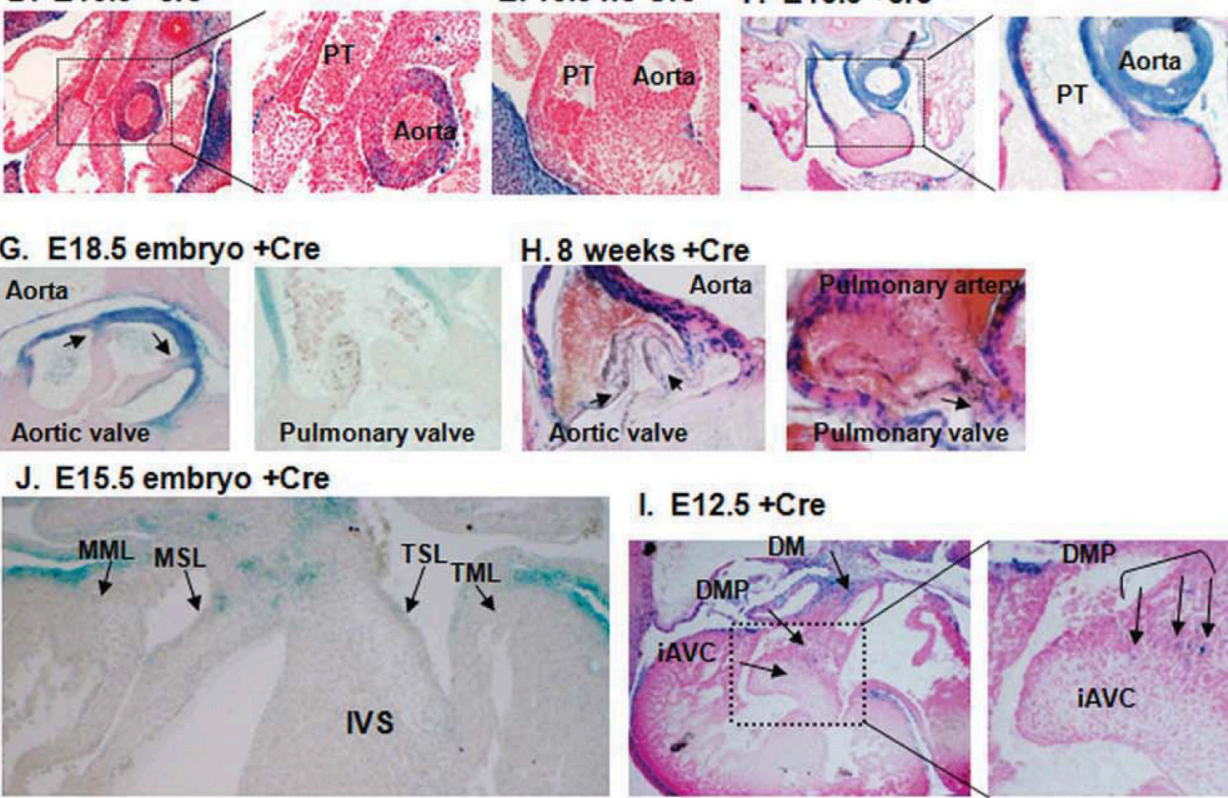

\section{I. $\mathrm{E} 12.5+\mathrm{Cre}$}

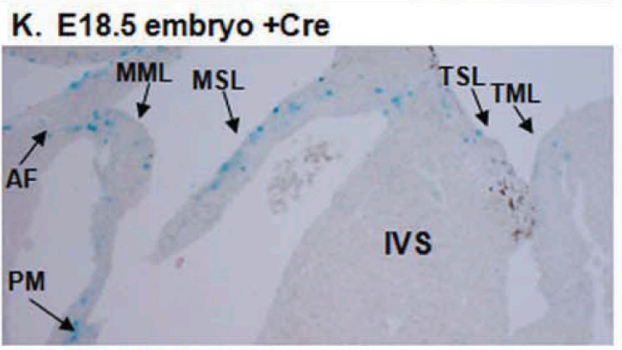

\section{N13.5 pup +Cre}
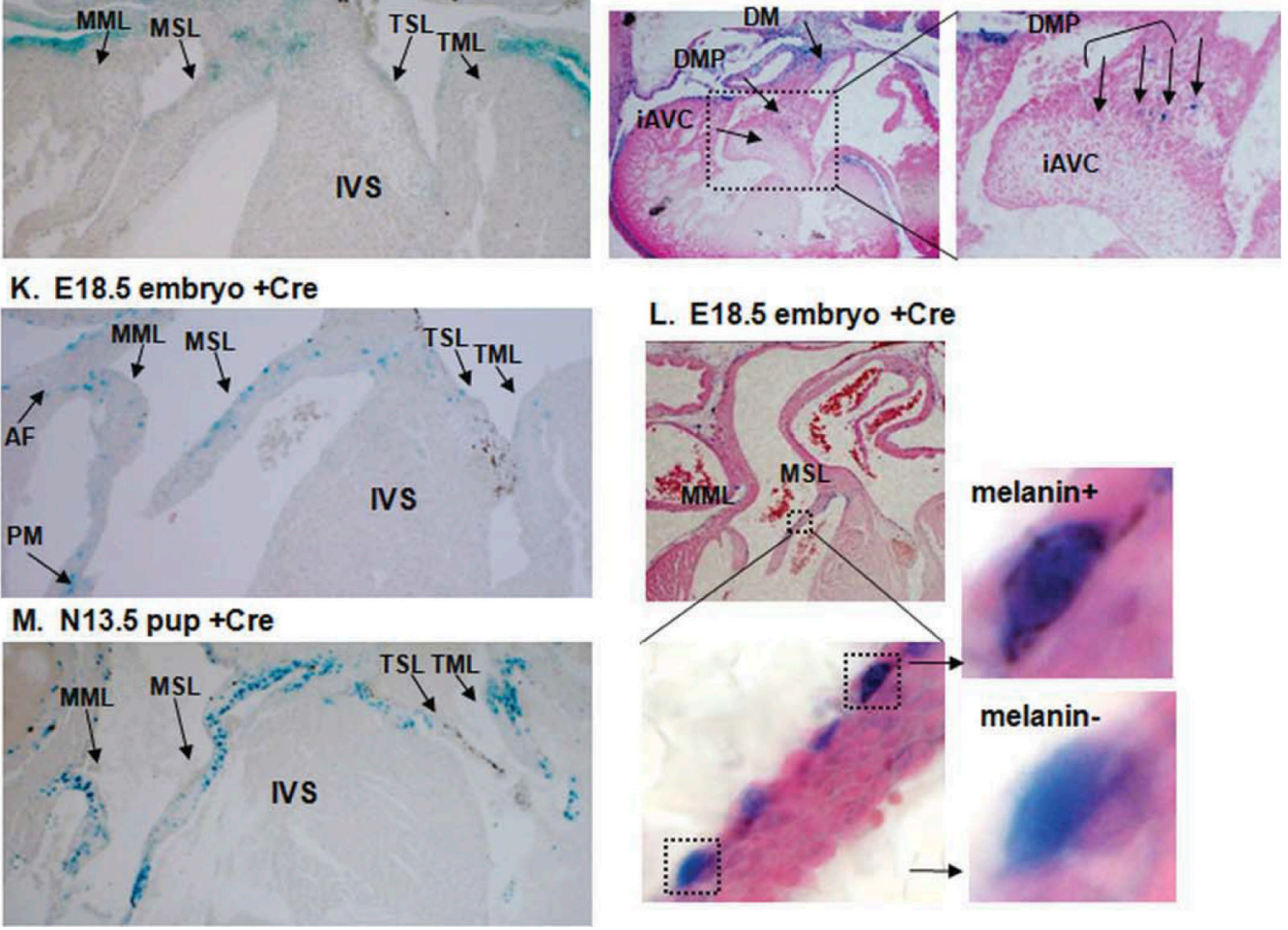

Fig. 3. Recombined Reporter Gene Expression in valve progenitors, valves, aorta and pulmonary trunk

Sections of whole-mount $\beta$ gal-stained (blue) Cre-expressing embryos. A, B. $\beta$ gal-positive cells were present in the distal outflow tract cushions at E10.5. (A), and in the outlet septum at E13.5 (B) C. $\beta$ gal-stained cells were absent in the outlet septum of no Cre embryos. D. $\beta$ gal-positive cells were present in the aorta, but not in the pulmonary trunk (PT) of Creexpressing (+Cre) E13.5 embryos. E. No expression was observed in the aorta and pulmonary trunk of the no Cre mice. F. At E15.5, the reporter gene was strongly expressed in both the aorta and pulmonary trunk of Cre-expressing embryos. G. Before birth, recombined transgene expression was only detectable in the in the aortic, but not the 
pulmonary, valve near the attachment to the vessel wall. H. After birth, blue cells were observed throughout both aortic and pulmonary valves. I. At E12.5, transgene expression is found in dorsal mesocardium (DM), dorsal mesenchymal protrusion (DMP) and inferior atrioventricular cushion (iAVC). J-M. $\beta$ gal-positive cells were present at E15.5 in septal AV leaflets $(\mathbf{J})$ and at E18.5 (K) also in the mural AV leaflets mainly near the attachment to the annulus fibrosus (AF) and papillary muscle (PM). M. At N13.5, $\beta$ gal-positive cells were present mostly at ventricular side of the valves. Interventricular septum (IVS), mitral mural leaflet (MML), mitral septal leaflet (MSL), tricuspid septal leaflet (TSL), and tricuspid mural leaflet (TML). L. At E18.5, melanin positive cells co-localized with $\beta$ gal-stained nuclei (arrows and enlarged insets) in the MSL. 

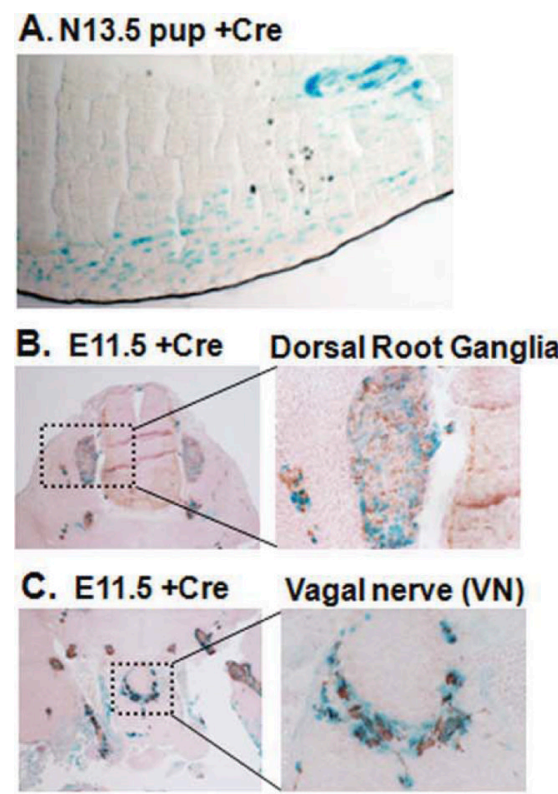

D. E11.5 no Cre
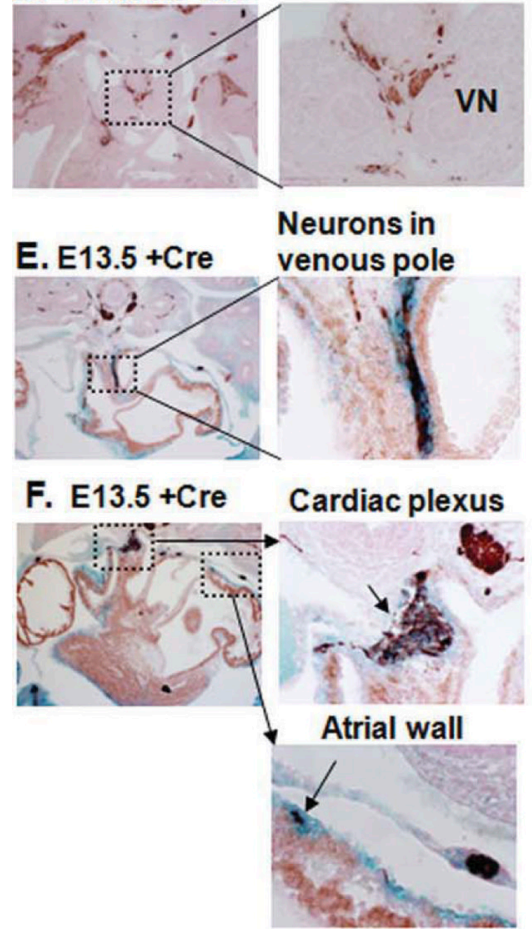

Fig. 4. Recombined Reporter Gene Expression in Other Tissues

A. $\beta$ gal-stained (blue) cells were observed within the compact layer of the ventricle of Creexpressing embryos (not shown) and pups. B - F. Sections of whole-mount $\beta$ gal-stained embryos were immuno-histochemically stained with an antibody against NF160 (brown). Cre-expressing (+Cre) embryos expressed the transgene strongly in NF160-positive cells in (B) dorsal root ganglia, (C) vagal nerve $(\mathbf{V N}),(\mathbf{E})$ venous pole $(\mathbf{V P}),(\mathbf{F})$ cardiac plexus (CP), and atrial wall (AW). (D) Mice with the intact (no Cre) transgene showed little, if any, $\beta$ gal-staining in these structures at all stages (E11.5 shown here; E14.5 not shown). 